\title{
PENGEMBANGAN METODE DUAL-FREKUENSI UNTUK MENGAMATI STRUKTUR VERTIKAL RAINDROP SIZE DISTRIBUTION (DSD) DI KOTO TABANG
}

\author{
Mutya Vonnisa $^{1^{*}}$, Toshiaki Kozu ${ }^{2}$ and Toyoshi Shimomai ${ }^{3}$ \\ ${ }^{1}$ Universitas Andalas, Sumatra Barat, Indonesia \\ ${ }^{2}$ Universitas Shimane, Matshue-Shi, Jepang \\ ${ }^{3}$ Universitas Shimane, Matshue-Shi, Jepang \\ *Email: mutya@fmipa.unand.ac.id
}

\begin{abstract}
ABSTRAK
Metode untuk mengamati struktur vertikal parameter mikrofisika hujan yang dikenal dengan DSD telah dikembangkan menggunakan data Equatorial Atmosphere Radar (EAR) dan Boundary Layer Radar (BLR) di Koto Tabang, Sumatera Barat, Indonesia. Spektrum hujan dari BLR yang merupakan fungsi DSD dimodelkan dengan modifikasi fungsi gamma dan spektrum turbulen atmosfir dari EAR dimodelkan dengan fungsi Gauss. Parameter DSD dan turbulen didapatkan dengan menggunakan metode non-linear least square fitting. Data dari Joss-Wadvogel Disdrometer (JD) digunakan untuk memvalidasi hasil yang didapatkan dari data radar. Hasil penelitian memperlihatkan bahwa metode dual-frekuensi lebih akurat dibandingkan dengan metode single-frekuensi. Hal itu ditunjukkan oleh hasil fitting spektrum hujan dari metode dualfrekuensi lebih tinggi dan jelas dibandingkan metode single-frekuensi. Selain itu DSD yang dihasilkan oleh metode dual-frekuensi lebih mendekati DSD dari JD dibandingkan dengan singlefrekuensi.
\end{abstract}

Kata Kunci: Raindrop Size Distribution, EAR, BLR, Koto Tabang

\section{PENDAHUHULUAN}

Pengetahuan tentang raindrop size distribution (DSD) merupakan hal yang penting di dalam pemodelan atmosfer global dan iklim. Pengukuran DSD bermanfaat untuk mempelajari mikrofisika hujan, dinamika awan, termodinamika atmosfer dan panas laten serta pengembangan metode remote sensing untuk pengamatan hujan. Sebagai parameter dasar hujan, maka semua parameter hujan adalah fungsi DSD.

Pengukuran DSD dapat dilakukan secara langsung atau tidak langsung, di tanah atau vertikal kolom hujan. Perolehan DSD secara langsung di tanah dapat menggunakan JD atau 2DVD (Two Dimensional Disdrometer). Sedangkan untuk struktur vertikal juga sudah dikembangkan oleh para peneliti dari data radar atmosfer, baik menggunakan metode satu frekuensi (single-frekuensi) ataupun dua frekuensi (dual-frekuensi).

Peneliti yang menggunakan metode single-frekuensi diantaranya: Sato et al. (1990), dan Wakasuki et al. (1986). Mereka memamfaatkan single-frekuensi dari VHF radar untuk memperoleh struktur vertikal DSD. Tetapi metode single frekuensi memiliki kelemahan karena kurang sensitif terhadap hujan, oleh karena itu dikembangkan metode dualfrekuensi. Seperti yang dilakukan oleh Teraoka et al. (1993) yang mengamati struktur vertikal DSD melalui pengamatan secara bersamaan antara VHF dan L-Band Doppler radar di Shigaraki. Selain itu, Schafer et al. (2002) juga mengamati struktur vertikal DSD dari dual-frekuensi wind profiler menggunakan teknik dekonvolusi dan nonlinear least square fitting.

Namun hasil DSD yang diperoleh dari kedua metode tersebut, bukanlah hasil global di seluruh permukaan bumi. Hal itu dikarenakan DSD bervariasi secara temporal dan spasial (Ulbrich, 1983), misalnya: karekteristik DSD di Shigaraki (Jepang) belum tentu sama 
dengan DSD di KotoTabang (Indonesia). Untuk penelitian struktur vertikal DSD di Koto Tabang telah dilakukan menggunakan metode single-frekuensi oleh beberapa peneliti (e.g., Kozu et al., 2003; Renggono et al., 2006; Marzuki et al., 2010). Semua penelitian sebelumnya menggunakan data Equatorial Atmosphere Radar (EAR). Penelitian di dalam artikel ini menghitung parameter DSD menggunakan dual-frekuensi, yaitu EAR yang beroperasi pada frekuensi $47 \mathrm{MHz}$ untuk mengukur turbulen dan Boundary Layer Radar (BLR) yang beroperasi pada frekuensi $1357.5 \mathrm{MHz}$ untuk mengukur hujan. Penelitian ini adalah yang pertama kali mengamati DSD menggunakan metode dual-frekuensi di Koto Tabang.

\section{DATA DAN METODE PENELITIAN}

\subsection{Data danInstrumen}

Tabel 1 menunjukkan spesifikasi dari EAR dan BLR. Penjelasan lebih detail tentang spesifikasi EARdiberikan oleh Fukao et al. (2003) dan BLR oleh Renggono (2006).

Tabel 1.Spesifikasi dari instrumen EAR dan BLR di Koto Tabang $\left(0.20^{\circ} \mathrm{S}, 100.32^{\circ} \mathrm{E}, 865\right.$ m ASL)

\begin{tabular}{|l|l|l|}
\hline Spesifikasi Instrument & EAR & BLR \\
\hline Radar system & $\begin{array}{l}\text { Monostatic Pulse Doppler } \\
\text { Radar }\end{array}$ & $\begin{array}{l}\text { Monostatic Pulse Doppler } \\
\text { Radar }\end{array}$ \\
\hline Center frekuensi & $47.0 \mathrm{MHz}$ & $1357.5 \mathrm{MHz}$ \\
\hline Antenna gain & $33 \mathrm{dBi}$ & $27 \mathrm{dBi}$ \\
\hline Antenna aperture area & $110 \mathrm{~m} \times 110 \mathrm{~m}\left(9500 \mathrm{~m}^{2}\right)$ & $5.9 \mathrm{~m}^{2}$ \\
\hline Antenna beam width & $3.4^{\circ}$ & $4.1^{\circ}$ \\
\hline Peak transmit power & $100 \mathrm{~kW}$ & $1.1 \mathrm{Kw}$ \\
\hline Pulse width & $0.5 \mu \mathrm{s}$ & $1 \mu \mathrm{s}$ \\
\hline IPP & $400 \mu \mathrm{s}$ & $100 \mu \mathrm{s}$ \\
\hline
\end{tabular}

EAR merupakan sebuah VHF-band wind profiler berfrekuensi $47 \mathrm{MHz}$. EAR dirancang agar mampu mengukur pergerakan angin di troposfir dan stratosfir bagian bawah atau dengan cakupan pengamatan pada ketinggian di atas $20 \mathrm{~km}$. Dalam kondisi tertentu, EAR dapat juga mendeteksi hujan tetapi dengan tingkat sensitivitas yang rendah (Fukao et al. 2003).

BLR merupakan sebuah UHF-band wind profiler berfrekuensi $1357.5 \mathrm{MHz}$ dengan transmisi daya $1 \mathrm{~kW}$. BLR didesain untuk dapat mengukur angin di troposfer bagian bawah termasuk planetary boundary layer (PBL) dengan resolusi waktu dan tinggi lebih kurang 1 menit dan 100 meter. Walaupun BLR didesain untuk pengamatan udara bersih, pengalaman menunjukkan bahwa BLR juga dapat digunakan untuk mendeteksi hydrometeors. Berbeda dengan EAR, pada saat hujan, echohujan dari BLR lebih kuat daripada echo turbulen. BLR bisa memperoleh echo hujan di atas $60 \mathrm{~dB}$ lebih kuat daripada echo turbulen atmosfer Renggono (2006). 


\subsection{MetodePenelitian}

\section{a. Model DSD}

Pada penelitian ini digunakan model gamma DSD sebagai berikut:

$$
N(D)=N_{0} D^{\mu} e^{-\Lambda D} .
$$

dimana $N(D)$ adalah DSD, $D$ adalah diamter butiran, $N_{0}$ adalah intercept, $\Lambda$ adalah slope dan $\mu$ adalah parameter bentuk. Pers. (1) dapat dimodifikasi menjadi bentuk lain dengan menggunakan momen ke-x dari DSD $\left(M_{x}\right)$ yang diberikan oleh persamaan:

$$
M_{x}=N_{0} \Gamma(\mu+x+1) / \Lambda^{\mu+x+1},
$$

dimana $\Gamma(\mu+x+1)$ adalah fungsi gamma. Menggunakan Pers. (2), Pers. (1) dapat ditulis sebagai berikut:

$$
N(D)=m_{y} \Lambda_{x y}^{x+y+1} D^{\mu} e^{-\Lambda_{x y} D},
$$

dimana $m_{y}=M_{y} / \Gamma(\mu+y+1)$ dan $\Lambda_{x y}=\left(m_{x} / m_{y}\right)^{1 /(y-x)}, \quad x=3.67$ dan $y=6$. Parameter DSD digambarkan oleh $m_{y}, \Lambda_{x y}$, dan $\mu$. $\Lambda_{x y}$ menunjukkan parameter skala $\Lambda$ yang diperoleh dari $M_{x}$ dan $M_{y}$. Pers. (3) didapatkan berdasarkan spektrum Doppler yang sebanding dengan $D^{6}|d v(D) / d D|^{-1}$ dimana $v(D)$ adalah kecepatan terminal. Fitting dari spektrum Doppler bisa dibuat secara efektif dengan menggunakan parameter DSD yang mempunyai sensitivitas yang tinggi terhadap spektrum Doppler (Kozu et al., 2003).

\section{b. Model Spektrum Doppler}

Untuk memperoleh DSD, membutuhkan spektrum hujan dan turbulen. Menurut Sato et al., (1990), spektrum hujan tanpa turbulen atmosfir dan angin $S_{p}(v)$ dituliskan oleh persamaan:

$$
S_{p}(v)=C N(D) D^{6}\left|\frac{d[v(D)]}{d D}\right|^{-1},
$$

Dimana $C$ adalah konstanta, $N(D)$ adalah DSD, $v(D)$ adalah kecepatan jatuh butiran. Fungsi Gauss digunakan untuk pemodelan spektrum turbulen $S_{t}(v)$ :

$$
S_{t}(v)=p_{0} \exp \left(-\frac{(v-w)^{2}}{2 \sigma^{2}}\right),
$$

dimana $p_{0}$ adalah puncak dari spektrum power, $w$ adalah kecepatan angin rata-rata dari radar beam direction, $\sigma$ lebar spektrum. Pada penelitian dual-frekuensi ini, EAR Doppler spektrum dari turbulen atmosfir $S_{E A R}(v)$ diberikan oleh:

$$
S_{E A R}(v)=\left[S_{t}(v)+P_{n}\right] * W(v),
$$

dimana $P_{n}$ adalah noise level pada spektrum, $W(v)$ adalah sebuah invers transformasi Fourier dari auto-correction function dari rectangular time window dan "." menunjukkan operasi integral konvolusi. Di sisi lain, BLR Doppler spektrum dari butiran hujan $S_{B L R}(v)$ ditunjukkan oleh persamaan berikut:

$$
S_{B L R}(v)=\left[S_{p}(v) * S_{0}(v)+P_{n}\right] * W(v),
$$


dimana $S_{o}(v)$ adalah bentuk normalisasi dari $S_{t}(v)$ yang diekspresikan oleh:

$$
S_{o}(v)=\frac{1}{(2 \pi)^{1 / 2} \sigma} \exp \left[-\frac{(v-w)^{2}}{2 \sigma^{2}}\right] \text {. }
$$

\section{c. Non-linear least square fitting dan MetodeDual frekuensi}

Parameter DSD didapatkan menggunakan non-linear least square fitting LevenbergMarquardt. Delapan parameter yang akan diperkirakan dengan fitting empat diantaranya berasal dari EAR turbulen spektrum yakni; $w, \sigma_{E}, p_{0}, P_{n}$ dan empat lainnya dari spektrum hujan BLR yakni; $m_{6}, \Lambda_{x y}, \mu$, dan $P_{n}$.

Untuk menghubungkan data dari EAR dengan BLR pada metode dual-frekuensi, kita harus membuat sebuah beam broadening correction. Persamaan untuk beam broadening correction ditunjukan oleh Pers. (9).

$$
\sigma_{B}{ }^{2}=\sigma_{E}{ }^{2}+C v_{h}{ }^{2}\left\{\left(\frac{\theta_{B}}{\theta_{E}}\right)^{2}-1\right\}, \quad C=\frac{\theta_{B, E A R}^{2}}{16 \cdot \ln 2}, \quad v_{h}=\sqrt{v^{2}+u^{2}}
$$

dimana $v_{h}$ adalah kecepatan udara horizontal. Nilai $v_{h}$ diperoleh dari kecepatan pergerakan angin ke utara $(v)$ dan kecepatan pergerakan angin ke timur $(u)$. Sebagai hasilnya, didapatkan mean Doppler spektrum $(w)$ dan standar deviasi spektrum BLR $\left(\sigma_{B}\right)$ dari spectrum EAR. Setelah itu dilanjutkan ke spectrum hujan BLR untuk mendapatkan nilai $\mu$ melalui proses iterasi. Nilai $\mu$ terbaik dilihat dari nilai minimum RMS error antara spektrum pengukurandan fitting. Setelah $\mu$ didapatkan, dua parameter DSD yang lain dari Pers. $3\left(m_{6}, \Lambda_{x y}\right)$ dapat dihitung.

\section{HASIL}

\subsection{Perbandingan Metode Single dan Dual FrekuensiBerdasarkanSpektrum.}

Contoh spektrum pengukuran dan fitting dari hujan ringan $(5 \mathrm{~mm} / \mathrm{jam})$ dan hujan deras $(11 \mathrm{~mm} / \mathrm{jam})$ pada ketinggian $2890 \mathrm{~m}$ di atas permukaan tanah, secara berturut-turut dapat dilihat pada Gambar 1 dan 2. Gambar 1(a) menunjukkan contoh single-frekuensi spektrum EAR yang dibandingkan dengan hasil fitting. Gambar 1(b) juga menunjukkan spektrum fitting dan pengukuran pada metode EAR dual frekuensi, dimana fitting hanya pada spektrum turbulen. Gambar 1(c) menunjukkan spektrum curah hujan pengukuran dan fitting dengan menggunakan metode BLR dual-frekuensi. Dari Gambar. 1, dilihat bahwa hasil dari metode dual-frekuensi lebih baik daripada metode single-frekuensi karena spektrum curah hujan terlihat lebih tinggi dan lebih jelas. Nilai fitting echo power spektrum hujan pada single-frekuensi sekitar $1 \mathrm{~dB}$, sedangkan pada dual-frekuensi sekitar $16 \mathrm{~dB}$. Untuk hujan deras (Gambar 2); nilai fitting echo power spektrum hujan pada single-frekuensi sekitar $6 \mathrm{~dB}$, sedangkan pada dual frekuensi sekitar $21 \mathrm{~dB}$. Puncak spektrum pada hujan deras dalam spektrum BLR lebih kuat dari pada hujan ringan dan terfitting dengan baik. Ini akan digunakan untuk memperoleh parameter DSD pada tahap berikutnya. 

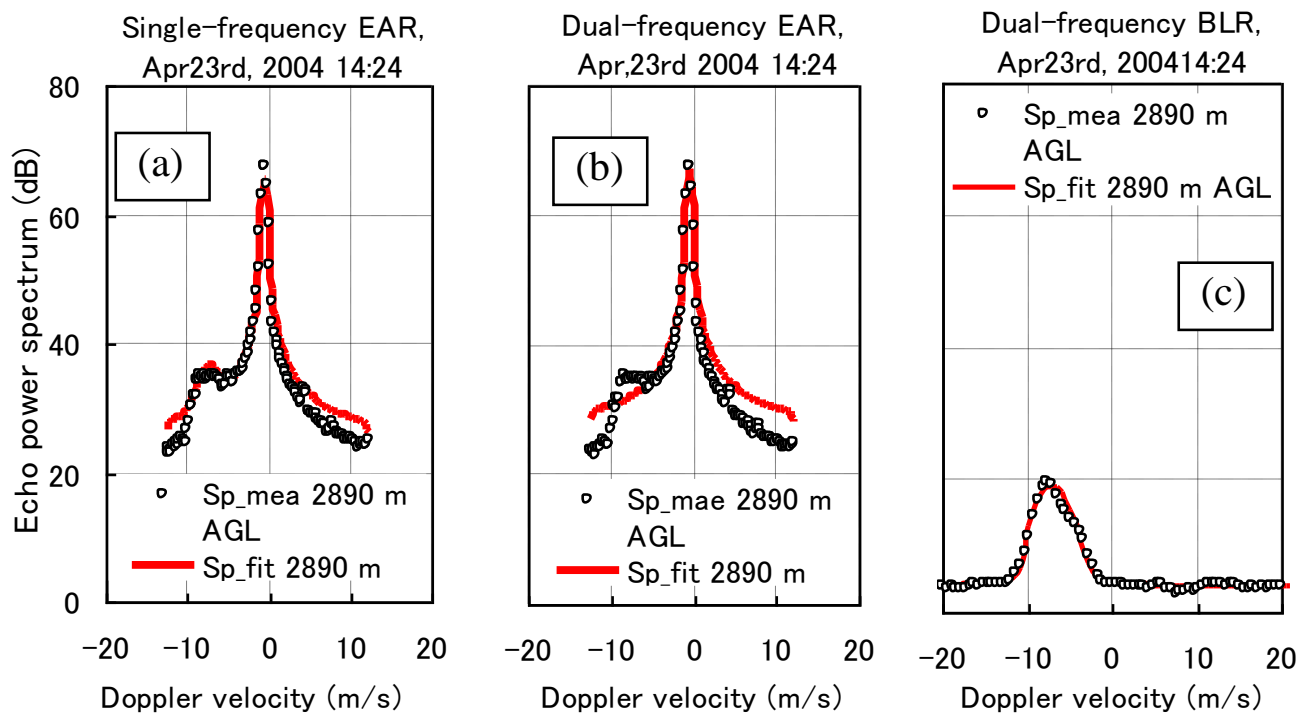

Gambar 1. Plot dari spektrum pengukuran dan fitting dari hujan ringan pada ketinggian $2890 \mathrm{~m}$ di atas permukaan tanah, Rainratedari Joss-Disdrometer: $5.138 \mathrm{~mm} / \mathrm{h}$.(a) single frekuensi EAR (b) dual-frekuensi EAR (c) dual-frekuensi BLR. Bulatan adalah spektrum pengukuran dan garis tebal adalah fittings pektrum.
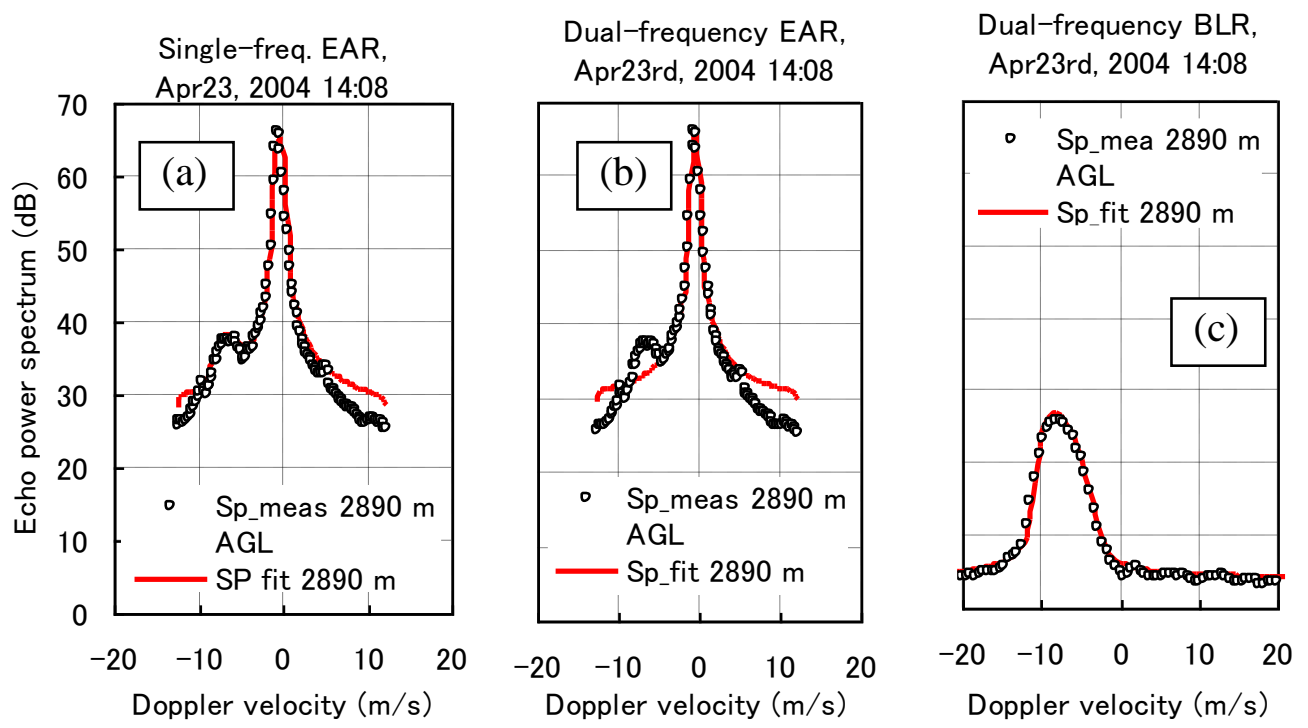

Gambar 2. Plot dari spektrum pengukuran dan fitting dari hujan deras pada ketinggian $2890 \mathrm{~m}$ di atas permukaan tanah, RainrateJoss-Disdrometer: $11.097 \mathrm{~mm} / \mathrm{h}$. (a) single frekuensi EAR (b) dual-frekuensi EAR (c) dual-frekuensi BLR. Bulatan adalah spektrum pengukuran dan garis tebal adalah fittingspektrum.

\subsection{Profil DSD dari Metode Single dan Dual Frekuensi.}

Gambar 3 menunjukkan DSD pada ketinggian 3340m di atas permukaan tanah untuk hujan berintensitas antara 5 dan $11 \mathrm{~mm} / \mathrm{jam}$ yang diperoleh dari data tanggal 23 April 2004. Terlihat dengan jelas bahwa DSD dari metode single-frekuensi sangat berbeda dari DSD yang didapatkan oleh JD. 

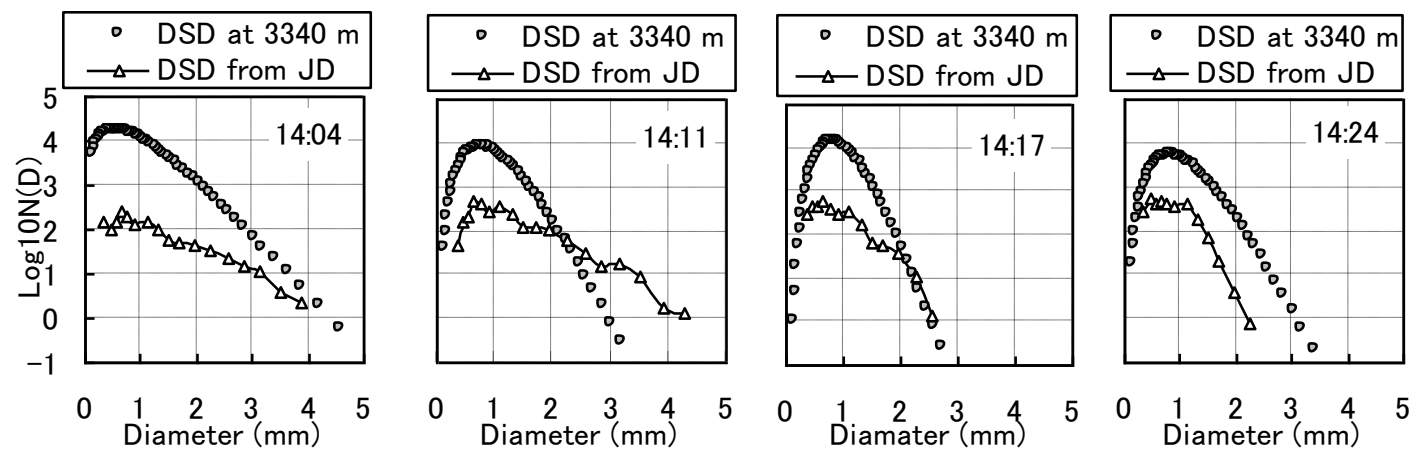

Gambar 3. Perbandingan DSD Single-frekuensidan Joss-Disdrometer dari data tanggal 23 April 2004 pukul 14:04 sampai 14:24.

Gambar 4 menunjukkan perbandingan DSD menggunakan metode dual-frekuensi dengan data Joss-disdrometer pada periode dan ketinggian yang sama dengan Gambar. 3. Hasil DSD dari metode dual-frekuensi terlihat lebih cocok dengan DSD yang diamati oleh Jossdisdrometer. Joss-disdrometer memiliki kemampuan untuk mengukur DSD secara langsung. Dengan demikian hasil yang ditunjukkanpada Gambar. 3 dan 4 menunjukkan bahwa vertikal profi DSD yang diperkirakan dengan menggunakan metode dualfrekuensi, menunjukkan hasil yang lebih baik daripada metode single-frekuensi.
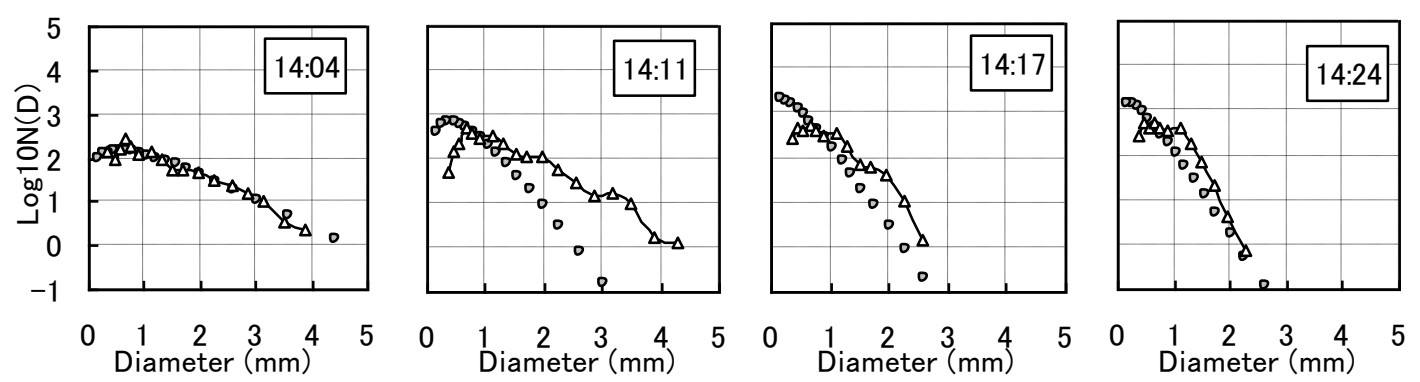

Gambar 4. Perbandingan DSD Dual-frekuensi dan Joss-Disdrometer dari data tanggal 23 April 2004 pukul 14:04 sampai 14:24.

\section{KESIMPULAN}

Hasil penelitian ini telah memperlihatkan bahwa metode dual-frekuensi lebih baik dibandingkan metode single frekuensi untuk mendapatkan struktur vertikal DSD di Koto Tabang. Hal itu diperlihatkan oleh fitting spektrum hujan pada dual-frekuensi terlihat lebih tinggi dan lebih jelas dibandingkan single frekuensi. Selain itu, data JD sebagai pembanding pada penelitian ini, dimana profil DSD menggunakan dual-frekuensi lebih memiliki fitting yang cocok dengan data Joss-disdrometer. Di dalam penelitian ini telah dianalisa hanya beberapa studi kasus saja. Oleh karena, diperlukan penelitian yang lebih lanjut dengan menggunakan data yang lebih banyak.

\section{DAFTAR PUSTAKA}

1. Kozu, T., K. K. Reddy, T. Shimomai, H. Hashiguchi, Y. Ohno, and S. Minami, 2003: Estimation of raindrop size distribution profile with atmosphere radars at south India and Sumatera, Japanese URSI-F meeting, No.473, Osaka Pref. Univ.

2. Madden and Julian, 1994: Observations of the 40-50 Day Tropical Oscillation - A Review, Mon. Wheather Rev., Vol. 122, 814-837. 
3. Maigure, II. W. B., andS. K. Avery, 1994: Retrieval of raindrop size distributions using two Doppler wind profiler: Model sensitivity testing, J. Appl. Meteor., Vol. 33,1623-1635.

4. Marzuki, T. Kozu, T. Shimomai, W. L. Randeu, H. Hashiguchi, and Y. Shibagaki, 2009: Diurnal variation of rain attenuation obtained from measurement of raindrop size distribution in equatorial Indonesia, IEEE Trans. Ant. Propag., Vol. 57, No.4, Pt.II, 1191-1196.

5. Renggono, F., M. K. Yamamoto, H. Hashiguchi, S. Fukao, T. Shimomai, M. Kawashima, and M. Kudsy, 2006: Raindrop size distribution observation with Equatorial Atmosphere Radar (EAR) during the CPEA-I observation campaign, Radio Sci., Vol. 41, 1-10.

6. Renggono, 2006: Study on precipitating clouds over Kototabang, West Sumatera observed by wind profilers, Renggono`s Thesis, submitted Kyoto University.

7. Sato, T., H. Doji, H. Iwai, and I. Kimura, 1990 : Computer processing for deriving drop-size distribution and vertical air velocities from VHF Doppler radar spektrum, Radio Sci., Vol. 25, 961-973.

8. Schafer, R., S. Avery, P. May, D. Rajopadhyaya, and C. Williams, 2002: Estimation of rainfall drop size distribution from Dual-frekuensi wind profiler spektrum using deconvolution and a non-linear least squares fitting technique, J. Atmos. Ocean. Tech. Vol. 19,864-874.

9. Ulbrich, C. W. (1983). Natural variations in the analytical form of the raindrop size distribution. J. Climate Appl. Meteor., 22, 1764-1775

10. Wakasugi, K., A. Mizutani, M. Matsuo, S. Fukao, and S. Kato, 1986: A direct method for deriving drop-size distributions and vertical air velocities from VHF Doppler radar spectra. J. Atmos. Oceanic Technol., 3, 623-629

11. Williams, C. R., W. L. Ecklund, and K. S. Gage, 1995: Classification of precipitating clouds in the Tropics using 915-MHz Wind Profiler, J. Appl. Meteor., Vol. 12, 9961012. 